\title{
Tenåringsdrikking i utviklingspsykologisk perspektiv
}

\author{
Hilde Pape \\ UNGforsk, Munthes gt. 29, 0260 Oslo
}

\begin{abstract}
SAMMENDRAG
Hvorfor er alkohol så populært blant unge mennesker? Dette viktige spørsmålet har vært gjenstand for få empiriske studier. Forskningsbasert kunnskap om alkoholens positive sider og forsterkende egenskaper er derfor av begrenset omfang. Derimot har tallrike undersøkelser fokusert på ulike skadevirkninger som følge av tenåringsdrikking. Resultatene av denne forskningen har bidratt til å understreke behovet for en aktiv rusforebyggende innsats. Innsikt i alkoholens opplevde goder er imidlertid nødvendig for å kunne utvikle effektive forebyggingsstrategier. På denne bakgrunn er søkelyset i artikkelen rettet mot psykososiale funksjoner ved unge menneskers drikkevaner. Spørsmål knyttet til gruppepress og modell-læring vil også bli berørt. Hensikten er å formidle sentrale funn fra nyere forskning på feltet. Oppsummeringsvis tyder resultatene på at alkohol har en særlig appell til ungdom som er veltilpassede og sosialt anlagte. Samtidig ser det ut til at drikking kan bidra til å fremme utviklingsprosessen i ungdomstida, men at det primært handler om indirekte effekter. Hvilke implikasjoner de ulike funnene har mht. forebygging, er skissert i avslutningsdelen.
\end{abstract}

Pape H. Teenage alcohol use from the perspective of psychological development. Nor J Epidemiol 1996; 6 (1): 85-90.

\section{ENGLISH SUMMARY}

Why is alcohol so popular among young people? So far, few studies have addressed this important question. The body of scientific research on the positive and reinforcing aspects of drinking is accordingly of limited extent. Numerous studies have focused on the harmful effects of teenage alcohol use and the findings clearly underscore the importance of primary prevention. Knowledge about the perceived advantages of alcohol use is needed to develop effective preventive programs, however. On this background, the article focuses on psychosocial functions of youthful drinking. Findings from recent research regarding the link between alcohol use and various indicators of adolescent adjustment are reviewed. In conclusion, empirical evidence indicates that alcohol has a special appeal to well-adjusted adolescents. Indirectly, drinking may also promote sociability and psychological development in young people. The article also discusses the importance of peer pressure and social modelling. Finally, some implications for preventive efforts are outlined.

\section{INNLEDNING}

Ungdomsfylla gir berettiget grunn til bekymring. Internasjonal forskning viser at alkoholrelaterte skader og ulykker, samt voldsutøvelse som følge av drikking, står for en betydelig andel av dødsfallene blant unge menn $(1,2)$. Unge mennesker har dessuten en forhøyet tendens til å drikke seg fulle og til å utøve risikofylte eller sosialt uakseptable handlinger i påvirket tilstand (3-5). Nyere norsk forskning har videre funnet at ungdomstidas drikkevaner i stor grad danner "presedens" for alkoholkonsumet i voksen alder (6). Ungdom som drikker mye har med andre ord en klar tendens til å drikke mer enn andre også i voksen alder. Spesielt de som begynner svært tidlig med alkohol har en sterkt forhøyet risiko for framtidig misbruk og høykonsum (7-9).

Unge mennesker er en høyt prioritert målgruppe for rusforebyggende tiltak. Formålet med slike tiltak har primært vært å fremme en rusfri livsstil i de yngre generasjoner. En beslektet målsetting handler om å få ungdom til å utsette sin alkoholdebut lengst mulig. Til tross for en aktiv og omfangsrik innsats gjennom en årrekke, blant annet i regi av ungdomsorganisasjoner innen avholdsbevegelsen, har imidlertid unge mennesker det høyeste konsumnivået $\mathrm{i}$ befolkningen 
$(3,10)$. Videre er oppslutningen om en totalavholden livsstil i de yngre generasjoner svært lav (11). Selv blant ungdom med medlemskap i avholdsorganisasjonene er det relativt mange som drikker alkohol (12).

Hvorfor er alkohol så populært blant ungdom? Overraskende få forskere innen rusmiddelfeltet har vært opptatt av dette viktige spørsmålet (13). Innsatsen har primært vært rettet mot skadevirkninger og alkoholrelaterte problemer, og mot å identifisere ulike risikofaktorer for misbruksutvikling. Slik forskning har bidratt til å understreke behovet for en aktiv forebyggende innsats. For å utforme slike tiltak, med tanke på å oppnå størst mulig effekt, er det imidlertid også nødvendig med forskningsbasert kunnskap om alkoholens opplevde goder. På denne bakgrunn vil jeg rette søkelyset mot tenåringsdrikkingens psykososiale funksjoner og utviklingspsykologiske betydning.

\section{ALKOHOLBRUK SOM INGREDIENS I UNGDOMSTIDAS UTVIKLINGSPROSESS}

En tiltakende nysgjerrighet rettet mot atferd som primært hører voksenrollen til, er typisk tegn på at man er i ferd med å forlate barndommens rike. I ungdomstida blir denne nysgjerrigheten som regel omsatt i handling. De fleste opplever sitt første møte med alkohol i løpet av tenåringsfasen, og her til lands er det over $90 \%$ som noen gang har drukket innen overgangen til 20-årene (11). I gjennomsnitt finner beruselsesdebuten sted i 16-års alderen, mens første gangs alkoholinntak forekommer noe tidligere $(7,14)$.

Tenåringsdrikking kan betraktes som en symbolsk markering på at man har tredd inn $\mathrm{i}$ en ny og mer "avansert" rolle. I moderne, sekulariserte samfunn er det få andre atferdsmarkører eller rituelle handlinger som bidrar til å befeste en slik rolleforfremmelse $(15,16)$. Samtidig ser det ut til at denne type symbolske markeringer, på overganger mellom ulike livsfaser, tjener viktige sosiale og psykologiske funksjoner $\mathrm{i}$ de fleste kulturer (17). I den vestlige verden er tenåringsdrikking særdeles velegnet som atferdsmarkør på tilnærming til voksenverden. Foreldre og andre voksne autoritetsfigurer er som regel fordømmende og restriktive $\mathrm{i}$ sitt syn på alkoholbruk hos mindreårige (18). På den annen side er det jo slik at majoriteten av den voksne befolkningen $i$ vår kulturkrets faktisk drikker (1). Sånn sett fungerer de som rollemodeller for drikkeatferd, samtidig som de formidler at alkoholbruk er en distinkt form for sosialt akseptabel "voksenatferd".

Alkoholbruk blant tenåringer går ofte under betegnelsen "problematferd", dvs. atferd som betraktes som upassende eller uakseptabelt av voksensamfunnet (19), og som derfor gir opphav til generasjonsmotsetninger og konflikter mellom ungdom og foreldre. Utøvelse av mindre graverende problematferd kan imidertid bidra til å fremme unge menneskers psykologiske utvikling. Nettopp det å teste grenser, og tidvis å handle på tvers av foreldrenes ønsker, råd og formaninger, er som regel et viktig aspekt ved den identitetsfremmende løsrivelsesprosessen i tenårene (20). Slik utprøvingsatferd tydeliggjør, både for en selv og for andre, at man tar selvstendige beslutninger og at man i økende grad er i ferd med å frigjøre seg fra foreldrenes sfære. Samtidig representerer tenåringsdrikking en temmelig konvensjonell form for "opprør". På en og samme tid signaliserer de unges befatning med alkohol både egenrådighet og kopiering av et sentralt aspekt ved voksne menneskers samværsform. For unge gutter handler det å drikke også om sosialisering inn i en tradisjonelt utformet kjønnsrolle og om å forvalte en sosial identitet som mann $(21,22)$.

Jones \& Hartmann (23) har publisert interessante resultater når det gjelder sammenhengen mellom rusbruk og identitetsutvikling hos amerikansk ungdom. De analyserte et stort, representativt materiale, og fant at en moden identitet var relatert til et moderat konsum av alkohol og andre rusmidler. Ungdom med en mindre velutviklet identitetsstatus hadde enten et veldig høyt eller et svært lavt konsumnivå. Tegn på et uforløst avhengighetskompleks i forhold til egne foreldre var relatert til lavforbruk av rusmidler.

Pape \& Hammers (14) funn fra en landsrepresentativ norsk undersøkelse peker i samme retning. Studien avdekket at unge menn som unnlot å utforske alkoholens ruseffekt i løpet av tenårene viste tegn på en forsinket tilpasning til voksenrollen. Menn med en edruelig ungdomstid hadde blant annet en forhøyet tendens til å bli forsørget av foreldrene sine $\mathrm{i}$ voksen alder, og til å bli boende hjemme hos mor og far til de var langt inn i 20-årene. De var også sent ute med å etablere et fast parforhold.

Studier som spesifikt har rettet søkelyset mot avholdsungdom har gitt liknende resultater. Sammenliknet med jevnaldrende alkoholbrukere, er avholdsungdom mer tilbøyelige til å bli kontrollert av foreldrene sine og til å ha sterke følelser av forpliktelse og lojalitet overfor dem $(24,25)$. Det har også blitt rapportert at avholdsungdom ofte har et "sammensmeltet" forhold til familien sin (26). De emosjonelle båndene til mor og far er med andre ord så tette at muligheten for individuell autonomi er begrenset. Ungdom som ikke drikker alkohol utmerker seg videre ved at de svært ofte deler foreldrenes holdninger, verdier og livssyn $(24,25,27)$. Dessuten er de i utpreget grad lovlydige og konforme, og tilbøyelige til å underkaste seg idealer som de voksne ønsker at ungdom skal leve opp til $(12,25)$. Et fravær av alderstypisk grensetesting og ungdommelig opposisjonslyst framstår som karakteristisk. Unge høykonsumenter har på sin side en tendens til å overreagere i motsatt retning (25). Uten dermed å si noe om mulige årsaksforklaringer, indikerer refererte resultater at et moderat alkoholkonsum inngår som en ingrediens $i$ ungdomstidas normalpsykologiske utviklingsforløp. 


\section{PSYKOSOSIALE ASPEKTER VED TENÅRINGSDRIKKING}

Ungdom er eksponert for tallrike innflytelsesrike rollemodeller for alkoholbruk. Sosialiseringen på dette området starter allerede i tidlig barndom, og nyere britisk forskning har vist at selv førskolebarn har relativt inngående kunnskap om alkohol og beruselse (28). Foreldrenes drikkevaner er et viktig inntak til denne type læring. Langt på vei er det også slike intrafamiliære læringsprosesser som ligger til grunn for den veldokumenterte sammenhengen mellom foreldrenes og de unges konsumnivå (29).

Blant tenåringer vil venner, i sterkere grad enn før, fungere som referanseramme og identifikasjonsfigurer, både på godt og vondt. Alkoholens betydning i denne sammenheng handler blant annet om å signalisere en tilknytning til jevnaldergruppa, og om å slutte seg til de normer og verdier som preger ungdomskulturen (30,31). I ungdomstida er anerkjennelse og aksept fra venneflokken dessuten et svært viktig bidrag til selvfølelsen (32). Samtidig ser det ut til at tenåringsdrikking er forbundet med bekreftelse og oppmuntring fra venner, mens avhold sjelden gir opphav til tilsvarende reaksjoner (33). Det er også avdekket at avholdsungdom ofte blir betraktet som lite opprørske og tøffe av sine jevnaldrende, og at de også har en tendens til å oppfatte seg selv på samme måte (27). En viss porsjon tøffhet er samtidig en egenskap som gjerne gir status i venneflokken, mens det motsatte trolig har en "diskvalifiserende" effekt, i hvert fall for gutter.

Gruppepress blir ofte framsatt som en viktig forklaring på unge menneskers delaktighet $\mathrm{i}$ ulike typer problematferd, alkoholbruk inkludert. En viktig forebyggingsstrategi har derfor gått ut på å lære barn og unge ferdigheter som gjør dem bedre rustet til å avvise andres oppfordringer om å drikke. Nyere forskning tyder imidlertid på at ungdom sjelden utsetter hverandre for slike eksplisitte anmodninger $(34,35)$. Oftest dreier det seg om indirekte former for sosialt press. Den enkeltes subjektive oppfatninger av andres alkoholrelaterte normer, forventninger eller atferd, er av sentral betydning i så henseende. Slike oppfatninger har på sin side en tendens til å avvike fra de faktiske forhold. Nærmere bestemt er ungdom tilbøyelige til å tro at andre unge har normer som er mer nonkonforme enn deres egne $(36,37)$, og til å overestimere alkoholkonsumet hos sine jevnaldrende $(38,39)$. Dermed oppstår det et fiktivt drikkepress i den enkeltes subjektive opplevelsesverden. Denne tendensen til å overestimering har vist seg å predikere initiering av alkoholbruk hos ungdom i pubertetsalder (40).

Enten det er snakk om direkte eller indirekte påvirkningsprosesser, impliserer betegnelsen "gruppepress" at det er "de andre" som påvirker det enkelte individ. Tallrike studier av ungdom har dokumentert til dels sterke sammenhenger mellom den enkelte og vennenes drikkevaner (41), men slike resultater kan ikke uten videre fortolkes som et uttrykk for effekten av sosial påvirkning. Også seleksjonsprosesser spiller en viktig rolle. Et av de mest konsistente funnene innen sosialpsykologien handler nettopp om at det ikke er tilfeldig hvem man velger å bli venn med (42). At likhet virker tiltrekkende er et meget veldokumentert fenomen. Det er blant annet vist at individer som etablerer et vennskapsforhold har en tendens til å matche hverandre langs ulike livsstilsvariable i utgangspunktet. Når det gjelder sammenhengen mellom eget og vennenes cannabisbruk, tyder amerikansk forskning på at den relative betydningen av henholdsvis ikke-tilfeldig valg av venner og modell-læring er omtrent like stor (43).

\section{ALKOHOLBRUK OG SOSIABILITET}

Flere studier har spurt ungdom direkte om hvorfor de drikker alkohol. Resultatene viser at drikking svært ofte handler om å feire sosiale begivenheter, om å ha det hyggelig og morsomt sammen med venner, og om å bli i godt humør $(44,45)$. Slike positive aspekter ved drikking er selvsagt ikke forbeholdt ungdom. Sammenliknet med andre aldersgrupper, rapporterer imidlertid unge mennesker oftere at de blir utadvendte og sosialt anlagte når de drikker, og at evnen til fortrolighet og nærhet tiltar $(4,46)$. Mange unge opplever også at alkohol gjør det lettere å nærme seg det motsatte kjønn. Ettersom tenåringer ikke har et etablert atferdsrepertoar knyttet til flørt og erotisk kontaktsøking, verdsetter de sannsynligvis slike alkoholrelaterte effekter særskilt høyt.

Alkoholbruk kan med andre ord bidra til å fremme mellommenneskelig samhandlig på en fordelaktig måte. Nyere forskning har også avdekket positive sammenhenger mellom konsumnivå og ulike mål på sosiabilitet. Ungdom som utmerker seg ved å være utadvendte, fritidsaktive og ved å ha nære, gode vennskapsrelasjoner, har også en tendens til å drikke mye $(37,47,48)$. Avholdsungdom peker seg ofte ut $\mathrm{i}$ motsatt retning $(12,49)$. Enkelte funn tyder på at også ekstreme høykonsumenter har en forhøyet tendens til å være upopulære og venneløse, og til å vise andre tegn på sviktende sosiale ferdigheter (49).

Få studier har forsøkt å avdekke hva som ligger til grunn for sammenhengen mellom alkoholbruk og sosiablitet. I Pedersen \& Aas' (7) longitudinelle studie av Oslo-ungdom ble det imidlertid funnet klare seleksjonseffekter når det gjaldt avhold. Resultatene viste at fravær av nære, fortrolige venner i tidlige tenår var prospektivt relatert til ikke-drikking ved utgangen av tenåringsfasen. En amerikansk undersøkelse har kommet fram til liknende funn mht. marijuanabruk (50). Da respondentene var i slutten av tenårene ble det avdekket en J-formet sammenheng mellom konsumnivå og psykososial mistilpasning. Ungdom som bare 
såvidt hadde prøvd marijuana var med andre ord de mest velfungerende. En tidligere kartlegging av det samme utvalget viste imidlertid at ikke-brukerne og høykonsumentene pekte seg ut i negativ retning allerede i barndommen. Barn som på et senere tidspunkt eksperimenterte med marijuana (uten å bli vanebrukere), kom best ut. Slike resultater tyder på at det er høy grad av stabilitet i psykososial fungering i løpet av oppveksten, og at eksperimentelt cannabisbruk bare er å anse som et korrelat til et gunstig utviklingsforløp.

Oppsummeringsvis synes vanlig brukte rusmidler å ha en særlig appell til tenåringer som i utgangspunktet er veltilpassede og sosiale. På den annen side er det avdekket at et moderat alkoholkonsum i midten av tenårene er prospektivt relatert til økt selvfølelse og bedret mental helse hos unge voksne (51). Det er også rapportert funn som tyder på at drikking kan bidra til å fremme unge menneskers sosiale integrering og tilknytning til venneflokken (52). Trolig er det slik at de som drikker øker sine relasjonsferdigheter ytterligere ved å bevege seg på arenaer der ungdom samles for å konsumere alkohol og for å utøve andre typiske "tenåringsaktiviteter". I så fall handler det om gunstige effekter av å ta del i det viktige jevnalderfellesskapet, og ikke om effekter av alkoholbruk som sådan. Likeledes kan det tenkes at de som i utgangspunktet hadde et skjørt sosialt nettverk beveger seg lenger ut $\mathrm{i}$ periferien hvis de ikke eksperimenterer med alkohol når de kommer i "drikkealder". Kanskje er det slik at avhold i ungdomstida signaliserer avstand til den dominerende ungdomskulturen, og en avvisning av de jevnaldrendes normer, verdier og livsstil.

\section{IMPLIKASJONER FOR FOREBYGGENDE TILTAK}

Tilgjengelig dokumentasjon tyder på at det er mange føringer som ligger til grunn for alkoholens popularitet blant ungdom. De fordelaktige kortsiktige virkningene blir verdsatt høyt, og samtidig bidrar drikking til å ivareta en rekke sosiale og utviklingspsykologiske funksjoner. I vår del av verden handler tenåringsdrikking blant annet om tilpasning til voksenrollen og om sosialisering inn i en kultur der alkohol har en solid forankring.
I samfunn der en overveldende majoritet av de voksne drikker alkohol, er avhold en lite realistisk målsetting for det primærforebyggende arbeidet rettet mot ungdom. Mye tyder dessuten på at avholdsungdom har en tendens til å framtre som lite egnede "ambassadører" for en alkoholfri livsstil overfor andre unge. Denne antakelsen understøttes av forskningsresultater som viser at de har en økt tilbøyelighet til å være foreldrebundne, og til å ha en svakt befestet posisjon i jevnaldergruppa. Ungdom som drikker relativt mye, derimot, har ofte egenskaper og ferdigheter som tilsier at de sannsynligvis fungerer som innflytelsesrike trendsettere og rollemodeller. Ved å gå aktivt inn med forebyggende tiltak er det imidlertid fullt mulig å få ungdom til å utsette sin alkoholdebut, i hvert fall for en kortere periode (53). En slik utsettelse har trolig gunstige langtidseffekter når det gjelder å demme opp mot en utviklig i retning av misbruk og høykonsum (7).

$\AA$ satse på økt kontroll og begrensning av unge menneskers tilgang på drikkevarer, er sannsynligvis en bedre forebyggingsstrategi enn å forsøke å påvirke dem til å velge et liv uten alkohol. Larsen \& Nergård (54) hevder i denne forbindelse at "et nærmest utopisk mål ville være at en fikk til holdninger i retning av at drikking var uforenlig med dans og moro" (s. 1076). En utfordring for det forebyggende arbeidet handler om å formidle kunnskap om hvordan man kan nyte alkohol på en måte som ikke medfører risikoeksponering eller overstadig beruselse. Også andre påvirkningsstrategier, i tillegg til denne type kunnskapsformidling, kan nyttiggjøres i en slik sammenheng. Opplæring i sosiale ferdigheter som gjør ungdom bedre rustet til å gripe inn overfor venner som drikker for mye, framstår som en annen viktig strategi. På dette området har nok også voksne mye å lære. Videre er det sannsynligvis viktig å realitetsorientere unge mennesker mht. de jevnaldrendes konsumnivå. En annen utfordring handler om å finne fram til gode alternativer til risikopreget alkoholbruk blant ungdom. Det vil si aktiviteter som bidrar til å befeste samhold og fellesskap, og som samtidig også kan fungere som atferdsmarkører på at man har forlatt barndommens rike.

\section{REFERANSER}

1. Edwards G, Anderson P, Babor TF, Casswell S, Ferrence R, Giesbrecht N, Godfrey C, Holder HD, Lemmens P, Mäkelä K, Midanik LT, Norström T, Österberg E, Romelsjö A, Room R, Simpura J, Skog O-J. Alcohol policy and the public good. Oxford: Oxford University Press, 1994.

2. Milgram GG. Adolescents, alcohol and aggression. Journal of Studies on Alcohol 1993; suppl. 11: 53-61.

3. Hauge R, Irgens-Jensen O. Alkoholen i Norden. Helsinki: Hakapaino OY, 1987.

4. Mäkelä K, Simpura J. Experiences related to drinking as a function of annual alcohol intake by sex and age. Drug and Alcohol Dependence 1985; 15: 389-404.

5. Temple MT, Fillmore KM. The variability of drinking patterns and problems among young men, age 16-31: A longitudinal study. International Journal of the Addictions 1985; 20: 1595-1620. 
6. Pape H, Hammer T. How does young people's alcohol consumption change during the transition to early adulthood? A longitudinal study of aggregate and individual level changes. Addiction (in press).

7. Pedersen W, Aas H. Full for første gang. Nordisk Alkohol Tidsskrift 1995: 12: 121-131.

8. Chou SP, Pickering RP. Early onset of drinking as a risk factor for lifetime alcohol-related problems. British Journal of Addiction 1992; 87: 1199-1204.

9. Rachal JV, Guess LL, Hubbard RL, Maisto SA. Alcohol misuse by adolescents. Alcohol Health and Research World 1992; 6: 61-68.

10. Saglie J. Norske drikkekulturer. Geografi, sosial bakgrunn, livsstil og tilgjengelighet. SIFA-rapport nr. 1/94. Oslo: Statens Institutt for Alkohol- og Narkotikaforsking, 1994.

11. SIFA. Rusmidler i Norge. Oslo: Statens Institutt for Alkohol- og Narkotikaforsking/Rusmiddeldirektoratet, 1995.

12. Pape H. Avholdsungdommens ulike ansikter. En studie av ungdom som ikke drikker alkohol og ungdom med medlemskap $i$ avholdsorganisasjonene. Oslo: Rusmiddeldirektoratet, 1996.

13. Pape H. Om alkoholforskningens problemorientering. Nordisk Alkohol Tidsskrift 1995; 12: 150-154.

14. Pape H, Hammer T. Sober adolescence - predictor of psychosocial maladjustment in young adulthood? Scandinavian Journal of Psychology (in press).

15. Pedersen W. Rites of passage in high modernity. Young 1994: 2: 21-32.

16. Pedersen W. Overgangsriter, liminalitet, rus. Nordisk Alkohol Tidsskrift 1992: 9: 98-107.

17. van Gennep A. The rites of passage. Chicago: Chicago University Press, 1960.

18. Manson L, Ritson B. Alcohol and health. London: Medical Council on Alcoholism, 1984.

19. Jessor R. Problem-behaviour theory, psychosocial development and adolescent problem drinking. British Journal of Addiction 1987; 82: 331-342.

20. Josselson R. Ego development in adolescence. I: Adelson J, red. Handbook of adolescent psychology. New York: John Wiley \& Sons, 1980: 188-210.

21. Lemle R, Mishkind ME. Alcohol and masculinity. Journal of Substance Abuse Treatment 1989; 14: 213-222.

22. Landrine H, Bardwell S, Dean T. Gender expectations for alcohol use: A study of the significance of the masculine role. Sex Roles 1988; 19: 703-712.

23. Jones RM, Hartmann BR. Ego identity: Developmental differences and experimental substance use among adolescents. Journal of Adolescence 1988; 11: 347-360.

24. Jessor R, Jessor SL. Adolescent development and the onset of drinking. Journal of Studies on Alcohol 1975; 36: $27-51$.

25. Demone HW. The nonuse and abuse of alcohol by the male adolescent. Proceedings of the Second Annual Conference of the National Institute on Alcohol Abuse and Alcoholism, Washington, D.C.: DHEW, 1972.

26. Protinsky H, Shilts L. Adolescent substance use and family cohesion. Family Therapy 1990; 17: 173-175.

27. Davies J, Stacy B. Teenagers and alcohol. A developmental study in Glasgow. London: HMSO, 1972.

28. Fossey E. Growing up with alcohol. London: Routhledge, 1994.

29. Barnes GM. The development of adolescent drinking behavior: An evaluative review of the impact of the socialization process within the family. Adolescence 1977; 12: 571-591.

30. Baumrind D. A developmental perspective on adolescent risk taking in contemporary America. I: Irwin CE, red. Adolescent social behavior and health. New directions for child development. San Francisco: JosseyBass, 1987: 93-125.

31. Jessor R. Adolescent development and behavioral health. I: Matarazzo JD, Weiss SM, Hers JA, Miller NE, red. Behavioral health: A handbook of health enhancement and disease prevention. New York: Wiley, 1984: 69-90.

32. Keefe K. Perceptions of normative social pressure and attitudes toward alcohol use: Changes during adolescence. Journal of Studies on Alcohol 1994; 55: 46-54.

33. Stumphauser JS. Learning not to drink: Adolescents and abstinence. Journal of Drug Education 1983; 13: $39-48$.

34. Savin-Williams RC, Berndt TJ. Friendships and peer relations. I: Feldman SS, Elliott G, red. At the threshold: The developing adolescent. Cambridge: Harvard University Press, 1990: 277-307.

35. Sheppard MA, Wright D, Goodstadt MS. Peer pressure and drug use: Exploding the myth. Adolescence 1985; 10: 949-958.

36. Pedersen W. The majority fallacy reconsidered. Acta Sociologica 1993: 36: 343-355. 
37. Baer JS, Stacy A, Larimer M. Biases in the perception of drinking norms among college students. Journal of Studies on Alcohol 1991; 52: 580-586.

38. Aas H, Klepp K-I. Adolescents' alcohol use related to perceived norms. Scandinavian Journal of Psychology 1992; 33: 315-325.

39. Bruun K, Hauge R. Drinking habits among northern youth. Helsinki: Finnish Foundation for Alcohol Studies, 1963.

40. Graham JW, Marks G, Hansen WB. Social influence processes affecting adolescent substance use. Journal of Applied Psychology 1991; 76: 291-298.

41. Hawkins JD, Catalano RF, Miller JY. Risk and protective factors for alcohol and other drug problems in adolescence and early adulthood: Implications for substance abuse prevention. Psychological Bulletin 1992; 112: 64-105.

42. Sabini J. Social Psychology. New York: W.W. Norton \& Company, 1995.

43. Kandel DB. Similarity in real life adolescent friendship pairs. Journal of Personality and Social Psychology 1978; 36: 306-312.

44. Johnston LD, O'Malley PM. Why do the nation's students use drugs and alcohol? Self-reported reasons from nine national surveys. Journal of Drug Issues 1986; 16: 29-66.

45. Lowe G, Foxcroft DR, Sibley D. Adolescent drinking and family life. Chur: Harwood Academic Publishers, 1993.

46. Hauge R, Irgens-Jensen O. The experiencing of positive consequences of drinking in four Scandinavian countries. British Journal of Addiction 1990; 85: 645-653.

47. Pedersen W. Forebyggende foreningsliv? Tidsskrift for Norsk Samfunnsforskning 1993; 34: 199-217.

48. Pedersen W. Ungdom, vennskap og bruk av rusmidler. Tidsskrift for Den Norske Lageforening 1993; 113: 1747-1749.

49. Leifman H, Kuhlhorn E, Andréasson P, Romelsjö A. Abstinence in late adolescence. Antecedents and covariates to a sober lifestyle and its consequences. Social Science and Medicine 1995; 41: 113-121.

50. Shelder J, Block J. Adolescent drug use and psychological health. A longitudinal inquiry. American Psychologist 1990; 45: 612-630.

51. Newcomb MD, Bentler PM. Consequences of adolescent drug use: Impact on the lives of young adults. Newbury Park: Sage, 1988.

52. Silbereisen RK, Noack P. On the constructive role of problem behavior in adolescence. I: Bolger N, red. Persons in context. Developmental processes. Cambridge: Cambridge University Press, 1988: 153-180.

53. Wilhelmsen B-U. Effekter av rusforebyggende undervisning: Erfaringer fra Bergensprosjektet "Unge og rusmidler". Paper presentert ved Rusmiddelforsknings-programmets avslutningskonferanse, Oslo, 24.-25. april 1996.

54. Larsen S, Nergård R. Rusmiddelforebyggende arbeid i skolen. Tidsskrift for Norsk Psykologforening 1991; 28: 1073-1078. 